\title{
Use of Granisetron for prevention of hypotension and bradycardia due to spinal anesthesia: A double blind randomised control trial.
}

\author{
Battu Kumar Shrestha*, Subhash Prasad Acharya**, Moda Nath Marhatta** \\ * Shahid Gangalal National Heart Centre, Bansbari, Kathmandu, Nepal. \\ ** Tribhuvan UniversityTeaching Hospital, Institute of Medicine, Kathmandu, Nepal.
}

Article History

Received

Accepted

$03^{\text {rd }}$ January 2014

$27^{\text {th }}$ February 2014

Published on print $01^{\text {st }}$ March 2014

Published online $24^{\text {th }}$ December 2014
(C) Authors retain copyright and grant the journal right of first publication with the work simultaneously licensed under a Creative Commons Attribution License that allows others to share the work with an acknowledgement of the work's authorship and initial publication in this journal.

\section{Abstract}

Background: The common adverse effects of spinal anaesthesia include hypotension and bradycardia are due to sympathetic nerve blockade and activation of the Bezold-Jarisch reflex. The Bezold-Jarisch reflex in spinal anaesthesia may be mediated by peripheral 5-HT3 type serotonin receptors. We hypothesized that blockade of type 3 serotonin receptors by using intravenous Granisetron might reduce hypotension and bradycardia induced by spinal anaesthesia.

Methodology: Sixty American Society of Anesthesiologists Physical Status I and II patients undergoing lower abdominal surgeries were randomized to receive either Normal Saline (control) or Granisetron $40 \mathrm{mcg} / \mathrm{kg}$ intravenously five minutes before subarachnoid block. Heart rates, systolic blood pressure, diastolic blood pressure, mean arterial pressure was recorded every two minutes for ten minutes and then every five minutes for another twenty minutes. Hemodynamic parameters were compared with baseline in each group.

Results: There was decrease in all measured variables when compared with baseline values in both groups. There was less reduction in diastolic blood pressure in Granisetron group statistically significant at 10, 15, 20, 25 and 30 minutes. However, the less decrease in mean arterial pressure was statistically significant at 30 minutes only. There were no significant differences in systolic blood pressure and heart rate values between the groups.

Conclusions: Granisetron given intravenously does not decrease the incidence of hypotension and bradycardia following subarachnoid block in patients undergoing lower abdominal surgery. However, it attenuates the fall of diastolic and mean arterial pressure spinal anaesthesia.

Key words: Granisetron; Hypotension; Spinal anaesthesia.

How to cite this article: Shrestha BK, Acharya SP, Marhatta MN. Use of Granisetron for prevention of hypotension and bradycardia due to spinal anesthesia: A double blind randomised control trial. JSAN 2014;1:36-39.

\section{Introduction}

The most common hemodynamic adverse effects of spinal anesthesia are hypotension and bradycardia. Incidence of hypotension is $33 \%$ (defined as systolic blood pressure $<90 \mathrm{mmHg}$ ) and that of bradycardia is $13 \%$ (defined as heart rate $<50$ beats $/ \mathrm{min}$ ) in non-obstetric populations. ${ }^{1}$ The decrease in preload caused by spinal anaesthesia may initiate vagally- mediated cardiodepressor reflexes, the Bezold Jarisch Reflex. ${ }^{2}$ It leads to shift in cardiac autonomic balance toward the parasympathetic nervous system. ${ }^{2}$ Different studies have shown that $5-\mathrm{HT} 3$ receptor 
antagonists like Ondansetron and Granisetron are effective in the prevention of spinal anaesthesia induced nausea, vomiting and shivering. ${ }^{3,4}$ Few other studies have shown the role of Ondansetron and Granisetron in the prevention of the Bezold-Jarisch reflex., ${ }^{5,6}$ The rationale of conducting this study was to explore whether Granisetron alone can prevent hypotension and bradycardia due to spinal anaesthesia.

\section{Material and methods}

The study was approved from Institution Review Board. Patients who fulfilled the inclusion criteria (American Society of Anesthesiologists Physical Status (ASA PS) I and II, age group 18 to 65 years) were enrolled. Written informed consent was taken from all the patients. The patients were randomly assigned into two groups (Group $\mathrm{G}$ and Group N), 30 patients in each group, by sealed envelope method. Group G patients received $40 \mu \mathrm{g} / \mathrm{kg}$ of Granisetron (Biogram-3) added to $0.9 \%$ of Normal Saline (NS) to make total volume of $5 \mathrm{ml}$. Group N patients received $5 \mathrm{ml}$ of $0.9 \% \mathrm{NS}$. All patients were pre-loaded with $10 \mathrm{ml} / \mathrm{kg}$ of Ringers Lactate and were transferred to Operating Room (OR). Baseline systolic blood pressure (SBP), diastolic pressure (DBP), mean arterial pressure (MAP) and heart rate (HR) were recorded. The study drug was prepared by Anaesthesia Assistant who was not involved in the study and calculated amount of study drug was given intravenously (IV) 5 minutes before the procedure. Subarachnoid block (SAB) was performed with $25 \mathrm{G}$ spinal needle (Quincke) at L3-L4 or L2-L3 space. After free flow of cerebrospinal fluid, $4 \mathrm{ml}$ of $0.5 \%$ hyperbaric Bupivcaine was injected over 15 to 20 seconds. The time of completion of sub-arachnoid injection was recorded as 0 min. After SAB, heart rate, SBP, DBP and MAP were recorded every 2 minutes for the first 10 minutes and then every $5 \mathrm{~min}$ for the subsequent 20 minutes. The sensory and motor block achieved was tested every 5 minutes till 15 minutes. Sensory level achieved was defined as the loss of cold sensation to spirit swab. The motor block achieved was graded according to the Bromage scale. The highest sensory and motor block obtained in 15 minutes were recorded for the study.

Hypotension was defined as an absolute decrease in SBP $<90 \mathrm{mmHg} .{ }^{1}$ If hypotension developed, it was first managed with fluid bolus of $4 \mathrm{ml} / \mathrm{kg}$. If it was not corrected with this, Mephentermine $6 \mathrm{mg}$ was given and was repeated after 3 minutes till it was corrected. Phenylepherine $50 \mu \mathrm{g}$ IV was kept as rescue drug when more than 30 $\mathrm{mg}$ of Mephentermine was required. Bradycardia was defined as absolute decrease in HR less than $50 / \mathrm{min}^{1}{ }^{1}$ It was treated with bolus Atropine $0.6 \mathrm{mg}$ and was repeated with similar dose subsequently till bradycardia was corrected. Total amount of IV fluid given in bolus, amount of vasopressor and Atropine required in first 30 minutes were recorded. Untoward effects like nausea, vomiting, shivering, restlessness or any significant hemodynamic changes till 4 hours from the time of administration of drugs (intraoperative, recovery, postoperative period) were noted in remarks.

\section{Statistical Analysis}

Data were recorded in preformed data collection Sheet. All data were entered in Microsoft office Excel worksheet 2007. For the analysis of the data, Statistical Package for the Social Sciences (SPSS) 17 was used. Sample size was calculated considering $\alpha=0.05, \beta=0.10$, Power $=90 \%$, with confidence interval obtained from the study of Radoslaw et al. ${ }^{8}$ STATA 9.0 (statistical software) was used for sample size calculation. Independent $t$ test was used for comparison between two groups. $p$ value less than 0.05 was considered significant.

\section{Results}

Sixty patients were enrolled in the study. There were no statistically significant differences between the groups with respect to demographic data (Table 1), baseline haemodynamic parameters, sensory and motor block obtained.

There was a trend of decrease in heart rate and systolic blood pressure in both groups after Sub-arachnoid Block. However, the difference in decrease was not statistically significant. There was statistically significant decrease in DBP in normal saline group in 10, 15, 20, 25 \& 30 minutes as compared to baseline (Figure 1).

There was trend in decrease in MAP in both groups. However, significant decrease was seen in Group N at 30 minutes $(p=0.03)$. There was no significant difference in development of adverse events like hypotension, bradycardia, nausea, vomiting and shivering between the groups till 30 minutes of study period (Table 2). Three patients in group $\mathrm{N}$ developed hypotension with nausea at 35, 40 and 45 minutes while one in group $\mathrm{G}$ developed hypotension at 40 minutes intraoperatively. All were managed with fluid bolus and Mephentermine $6 \mathrm{mg}$ IV bolus. 
Two patients, one in each group developed shivering in recovery room after one hour of surgery. Both were managed with inj. Pethidine $25 \mathrm{mg}$ IV stat.

Table 1. Demographic profiles

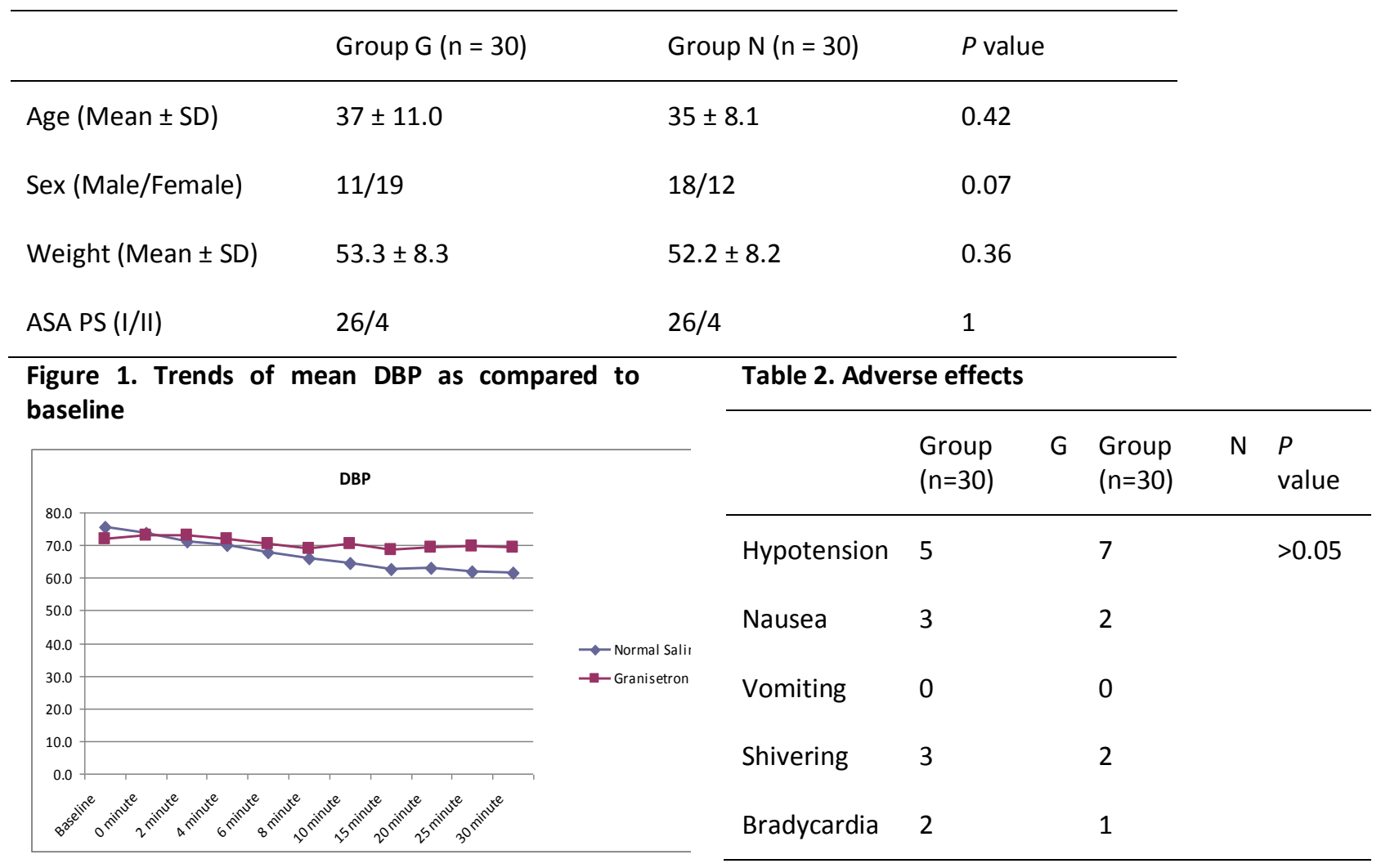

\section{Discussion}

Studies have revealed the effectiveness of different strategies for the prevention of spinal anaesthesia induced hypotension such as pre or co-loading of IV fluid, use of vasopressors and compression devices. ${ }^{9,10,11}$ However, a Cochrane review concluded that none of these techniques alone was sufficient in eliminating hypotension. ${ }^{12}$ This emphasized the need of the future research concerning other agents. This double blind randomized controlled study was designed to test the effectiveness of pretreatment with intravenous Granisetron for the prevention of spinal anaesthesia induced hypotension and bradycardia.

To prevent spinal anaesthesia induced hypotension and bradycardia, Granisetron, a 5-HT3 antagonist, was chosen in this study for following reasons: first, animal studies showed the effectiveness of Granisetron in the prevention of the Bezold Jarisch Reflex which also occurs following spinal anaesthesia due to severe decrease in preload. ${ }^{2,5,6}$ Second, Tsikouris et al found the role of Granisetron for the prevention of neurally mediated hypotension upon head upright tilt testing associated with systemic vasodilatation. ${ }^{7}$ Third, Radoslaw et al found that $8 \mathrm{mg}$ intravenous Ondansetron, another 5-HT3 antagonist, attenuates the SBP and MAP drop in spinal anesthesia and emphasized the need for further studies. ${ }^{8}$ Forth, Yeasmeen et al found that Granisetron is more effective than Ondansetron in the prevention and treatment of postoperative nausea and vomiting. ${ }^{13}$ So Granisetron was preferred over Ondansetron. Regarding the dose of Granisetron, Kamanabrou et al found $40 \mu \mathrm{g} / \mathrm{kg}$ as the optimal dose of Granisetron for chemotherapy induced vomiting. ${ }^{14}$ Tsikouris et al also used $40 \mu \mathrm{g} / \mathrm{kg}$ of intravenous Granisetron in their study for prevention of neurally mediated hypotension upon head upright tilt testing. ${ }^{7}$ So we decided to use $40 \mu \mathrm{g} / \mathrm{kg}$ of Granisetron.

The results of our study showed that pretreatment with $40 \mu \mathrm{g} / \mathrm{kg}$ of intravenous Granisetron does not prevent the incidence of hypotension and bradycardia following spinal anaesthesia for lower abdominal surgery in ASA I and II patients. However, this study showed the decrease in HR, SBP, DBP and MAP in both groups till 30 minutes of 
observation after spinal anaesthesia. This decrease was explained with the sympathetic blockade following sub arachnoid block. The decrease was significant for DBP 10, 15, 20, 25 and 30 minutes in Normal Saline group. The decrease in MAP was statistically significant only at 30 minutes in placebo group.

In the study conducted by Radoslaw et al there was significant decrease in SBP and MAP in control group as compared to treatment group (receiving $8 \mathrm{mg}$ of intravenous Ondansetron) following spinal anaesthesia with $4 \mathrm{ml}$ $0.5 \%$ hyperbaric Bupivacaine solution. ${ }^{8}$ Sahoo et al conducted a study using $4 \mathrm{mg}$ of intravenous Ondansetron in parturients undergoing caesarean section under spinal anaesthesia and found decrease in fall of SBP and MAP in treatment group. ${ }^{15}$ However, in our study, there was statistically significant decrease in reduction of DBP. The main difference between our study and studies of Radoslaw et al and Sahoo et al is the use of drug. Radoslaw et al and Sahoo et al used Ondansetron and we used Granistron. This could be possible reason for the difference in results.

Regarding the limitations of the study, we used oscillatory method for noninvasive blood pressure measurements. Invasive blood pressure monitoring would have been used for more precise assessment of hemodynamic changes. Amount of blood loss was not recorded in this study. This can influence the hemodynamic profile of patients. The study was conducted in ASA PS I \& II patients, low risk groups with stable hemodynamic. The result of this study may not be extrapolated to patients with high risk group. Absolute value was used in this study to define hypotension and bradycardia. Use of relative value (percentage reduction from baseline) in addition to absolute value may be more precise in defining hypotension and bradycardia when there is wide fluctuation in baseline values.

From this double blind, randomized, prospective study, it was concluded that Granisetron when given at $40 \mu \mathrm{g} / \mathrm{kg}$ intravenously 5 minutes before spinal anaesthesia does not decrease the incidence of hypotension and bradycardia. However, it attenuates the decrease in diastolic blood pressure.

\section{References}

1. Carpenter RL, Caplan RA, Brown DL, Stephenson C, Wu R. Incience and risk factors for side effects of spinal anesthesia. Anesthesiology 1992;76:906-16.

2. Campagna JA, Carter C. Clinical relevance of the Bezold-Jarisch Reflex. Anesthesiology 2003;98:1250-60.

3. Dasgupta M, Biswas BN, Chatterjee S, Mazumder P and Chowdhury MB. Randomized, placebo-controlled trial of Granisetron for control of nausea and vomiting during cesarean delivery under spinal anesthesia. J Obstet Gynaecol India 2012;62:419-23.

4. Shakya S, Chaturvedi A, and Sah BP. Prophylactic low dose Ketamine and Ondansetron for prevention of shivering during spinal anaesthesia. J Anaesthesiol Clin Pharmacol 2010;26:465-9.

5. White CM, Chow MS, Fan C, Kluger J, Bazunga M. Efficacy of intravenous Granisetron in suppressing the bradycardia and hypotension associated with a rabbit model of the Bezold-Jarisch reflex. J Clin Pharmacol 1998;38:172-7.

6. Yamano M, Kamato T, Nishida A, Ito H, Yuki H, Tsutsumi R, et al. Serotonin (5-HT)3-receptor antagonism of 4,5,6,7tetrahydrobenzimidazole derivatives against 5-HT-induced bradycardia in anesthetized rats. Jpn J Pharmacol 1994;65:241-8.

7. Tsikouris JP, Kluger J, Chow MS, White CM. Usefulness of intravenous Granisetron for prevention of neurally mediated hypotension upon head upright tilt testing. Am J Cardiol. 2000;85:1262-4.

8. Radoslaw O, Wojciech W, Agnieszka P, Pawel T, Renata A, Anna D, et al. Ondansetron given intravenously attenuates arterial blood pressure drop due to spinal anesthesia. Reg Anesth Pain Med 2008;33:332-9.

9. Buggy D, Higgins P, Moran C, O Brien D, O Donovan F, McCarroll M. Prevention of spinal anesthesia-induced hypotension in the elderly: comparison between preanesthetic administration of crystalloids, colloids, and no prehydration. Anesth Analg 1997;84:10610.

10. Hemmingsen C, Poulsen JA, Ribso A. Prophylactic ephedrine during spinal anaesthesia: double blind study in patients in ASA groups I-III. Br J Anaesth 1989:63:340-2.

11. Adsumelli RSN, Steinberg ES, Schabel JE, Saunders TA and Poppers PJ. Sequential compression device with thigh-high sleeves supports mean arterial pressure during Caesarean section under spinal anaesthesia. Br J Anaesth 2003:91:695-8.

12. Cyna AM, Andrew M, Emmett RS, Middleton P, Simmons SW. Techniques for preventing hypotension during spinal anaesthesia for caesarean section. Cochrane Database Syst Rev 2006:18:CD002251.

13. Yeasmeen S, Yasmin R, Akhtaruzzaman AKM, Khatun UHS. Intravenous Granisetron, Ondasetron and Metoclopromide in the prevention and treatment of post operative nausea and vomiting after laparoscopic Cholecystectomy - A comparative study. Journal of BSA, 2006:19:1-2.

14. Kamanabrou D. Intravenous Granisetron - establishing the optimal dose. The Granisetron Study Group. Eur J Cancer 1992;28A:S6S11.

15. Sahoo T, Sen Dasgupta C, Goswami A, Hazra A. Reduction in spinal-induced hypotension with Ondansetron in parturients undergoing caesarean section: A double-blind randomised, placebo-controlled study. International Journal of Obstetric Anesthesia 2012;21:24-8. 